\title{
Inferring versus measuring rates of recovery in no-take marine reserves
}

\author{
Garry R. Russ ${ }^{1, *}$, Brian Stockwell ${ }^{2}$, Angel C. Alcala ${ }^{2}$ \\ ${ }^{1}$ School of Marine Biology and Aquaculture, James Cook University, Townsville, Queensland 4811, Australia \\ ${ }^{2}$ Silliman University Angelo King Center for Research and Environmental Management, Silliman University, \\ Dumaguete City 6200, Philippines
}

\begin{abstract}
Can rates of biomass recovery of fished species be inferred reliably from once-only spatial comparisons of no-take marine reserves of different ages and fished areas? We used underwater visual census at 15 no-take marine reserves in the Philippines to both infer and measure such rates. We made a single estimate of the biomass of large predatory fishes (Serranidae, Lutjanidae, Lethrinidae) targeted heavily by fisheries in each of 13 well protected no-take reserves (age range 0.5 to $13 \mathrm{yr}$ ), and in nearby nonreserve (fished) sites. We also measured rates of biomass buildup of these fish regularly for 18 yr (1983 to 2001) in 2 no-take reserves (Sumilon, Apo) and nonreserve sites. The duration of protection required to detect significantly higher reserve biomass was similar, but lower for temporal monitoring ( 3 to $4 \mathrm{yr}$ ) than for spatial comparisons $(6 \mathrm{yr})$. The reserve:nonreserve biomass ratios at maximum duration of reserve protection were similar for inferred (9.0) and measured (6.3 to 9.8) estimates. Thus, results of long-term monitoring of 2 reserves may have regional generality. The inferred rate of change of a reserve effect index $(\log 10$ [Reserve biomass $+1 /$ Nonreserve biomass +1 ]) with duration of protection did not differ significantly from the measured rate at Sumilon, but was higher than that measured at Apo. A habitat complexity index did not affect estimates of 'reserve effects' significantly in this study, and reserve protection was generally effective. Thus, using similar methods of reserve protection and census on the same target group in similar areas, one can make useful inferences about rates of recovery in no-take marine reserves.
\end{abstract}

KEY WORDS: Coral reefs $\cdot$ Marine reserves $\cdot$ Recovery rates - Spatial comparisons - Temporal monitoring · Philippines

Resale or republication not permitted without written consent of the publisher

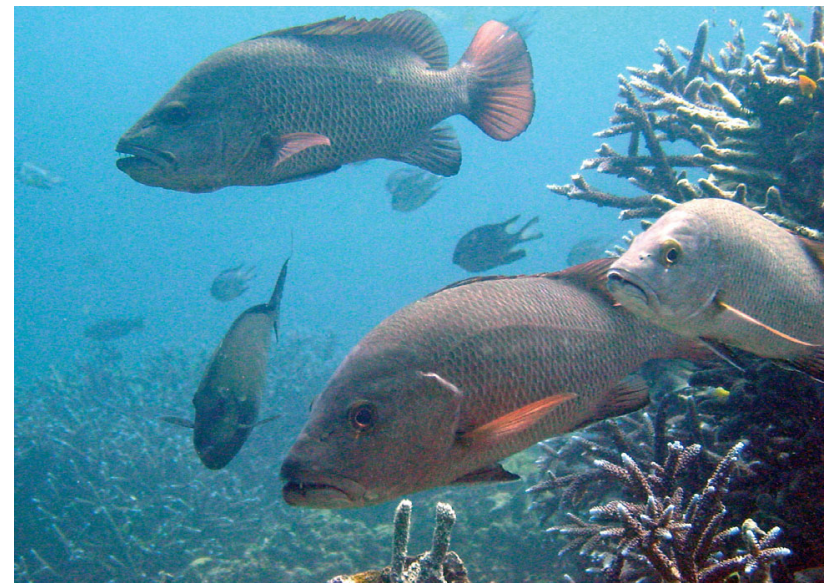

Over a period of almost two decades, the authors monitored biomass of large predatory coral reef fish, such as the snapper Lutjanus argentimaculatus (photo), inside and outside two small marine reserves in the Philippines. Photo taken in the Mesaplod Norte marine reserve by Jasper Maypa

\section{INTRODUCTION}

No-take marine reserves are areas where all forms of extraction, particularly fishing, are banned permanently (Roberts \& Polunin 1991, Dayton et al. 2000, Gell \& Roberts 2002). Such spatial management has been advocated as a solution to many important problems within the marine environment (Dayton et al. 2000, Gell \& Roberts 2002, Sobel \& Dahlgren 2004). These problems include loss of marine biodiversity (Jackson et al. 2001, Sobel \& Dahlgren 2004), alteration of trophic structures (Pauly et al. 1998, 2002, Babcock et al. 1999, Castilla 1999, Jackson et al. 2001, Babcock 2003), and chronic over-fishing (Pauly et al. 1998, 2002, Hutchings 2000, Jackson et al. 2001). At the same time, no-take marine reserves may provide social and eco- 
nomic benefits through enhanced tourism (Dayton et al. 2000, Gell \& Roberts 2002, Sobel \& Dahlgren 2004).

The main expectations of no-take marine reserves as fisheries management tools are that they will maintain segments of populations and ecosystems in natural states. In the case of exploited organisms, it is assumed that the protection of spawning biomass will lead to net export of adults and propagules that will sustain, and perhaps enhance, fisheries outside reserves in the long-term (Russ 2002). The amount of empirical data by which to judge these expectations of net export remains very limited. This is partly due to the paucity of well designed marine reserve experiments (Jones et al. 1993, Polunin 2002, Russ 2002, Willis et al. 2003a, Edgar et al. 2005). It is also due to a lack of clear knowledge of the rates of recovery of exploited organisms within no-take reserves (Russ \& Alcala 1996a, 2004, McClanahan 2000, Jennings 2001).

A range of views exists in the current literature regarding the rates of recovery of exploited organisms within no-take reserves. One view is that abundance of target species often increases rapidly following establishment of marine reserves (Roberts 1995, Halpern \& Warner 2002). Halpern \& Warner (2002) have even suggested, based on a meta-analysis of reserve studies, that most of the recovery process is rapid (occurring within 1 to $3 \mathrm{yr}$ ) and that abundance is subsequently consistent across reserves of all ages. On the other hand, both McClanahan (2000) and Russ \& Alcala (2004) have suggested that the duration of protection inside no-take reserves to ensure full recovery of predatory reef fish may take 3 to 4 decades. Part of this difference in perspective may be due to a lack of a clear definition of the degree of recovery. There is little doubt that initial rates of recovery of populations inside no-take reserves can be very rapid at certain times and places, even for organisms with life history characteristics that would suggest low rates of population turnover (McClanahan \& Kaunda-Arara 1996, Russ \& Alcala 1996a, 2003, Jennings 2001, Roberts et al. 2001, Denny et al. 2004). However, there are also clear demonstrations that the recovery process can continue for decades, and thus duration to full recovery will be considerable (Russ \& Alcala 2004). Clearly we need to know more about recovery rates inside marine reserves.

If the rates to full recovery inside no-take reserves range from rapid to slow for a large range of exploited marine organisms, it is tempting to try to infer such rates by simply comparing (once only) abundance of organisms inside and outside no-take reserves of different age. Such an approach clearly saves time, and can make use of considerable literature that reports such one-off spatial comparisons (e.g. Mosquera et al. 2000, Côté et al. 2001, Halpern \& Warner 2002,
Halpern 2003). The potential pitfalls of meta-analyses of spatial comparison type data to indicate levels of 'reserve effect' (greater abundance of targeted organisms inside than outside reserves) has been stressed by Edgar et al. (2005), who point to conclusions reached in meta-analyses by Halpern (2003) and Mosquera et al. (2000): that overall fish densities are on average $91 \%$ and $270 \%$ higher in reserves, respectively. However, a similar meta-analysis by Côté et al. (2001) revealed a non-significant increase in density of just $25 \%$. Thus, the estimates of reserve effect on overall fish density vary by more than an order of magnitude amongst just 3 meta-analyses, based almost solely on spatial comparison data.

If meta-analyses from the current marine reserve literature cannot conclude with confidence the degree of reserve effect, how much more difficult is it for meta-analyses to reach useful conclusions about the rates at which such effects develop? Inferring rates by simply comparing (once only) abundance of organisms inside and outside no-take reserves of different age often confounds the 'duration of reserve protection' effect with differences in habitat between reserve and fished areas; this is sometimes exacerbated if very good or very poor sites are chosen for reserves in the first place (Edgar et al. 2005), and control areas of similar habitat are unavailable for comparison. Such inferences are also confounded by differential poaching histories of reserves. In the case of meta-analyses that infer rates, such as that of Halpern \& Warner (2002), pooling across a range of life history characteristics will likely confound estimates of recovery rates of specific target groups. We concede that if the source publications on which such meta-analyses are based fail to provide detailed information on habitat, poaching history of reserves, or life history of target organisms, it is very difficult for the authors of these meta-analyses to control for such confounding effects.

A dichotomy exists in the literature on the utility of once-only spatial comparisons of reserve and fished areas to infer recovery rates. Halpern \& Warner (2002) examined 112 independent measurements of 80 reserves. Few (7) of these studies monitored variates of interest (e.g. abundance, diversity) over time. However, they concluded that ' ... the higher average values of density, biomass, average organism size, and diversity inside reserves (relative to controls) reach mean levels within a short ( 1 to $3 \mathrm{yr}$ ) period of time and that the values are subsequently consistent across reserves of all ages (up to $40 \mathrm{yr})^{\prime}$. They reached this conclusion by plotting reserve effect indices (log 10 ratios of density, biomass, average size and diversity inside and outside reserves) against reserve age. None of the slopes of the regressions of reserve value/fished value versus reserve age were significantly different from zero. Both Côté et al. 
(2001) and Russ (2002) independently showed that the slope of regressions of reserve density/fished density versus reserve age, derived from data from 19 and 16 reserves, respectively, were also not significantly different from zero. Côté et al. (2001) concluded that such reserve effect ratios were unrelated to years of reserve protection. Russ (2002) concluded that the spatial comparison evidence revealed little about rates of increase in density over time. He suggested further that such an approach could not indicate anything unequivocal about such rates.

In this study we ask whether rates of biomass recovery of fished species can be inferred reliably from once-only spatial comparisons of no-take reserves and fished areas. We used underwater visual census at 15 no-take marine reserves in the Philippines to both infer and measure such rates. We conclude that if one uses similar methods of reserve protection and census on the same target group in similar areas, and ensure that habitat and reserve effects are partitioned in analyses, one can make useful inferences about rates of recovery in no-take marine reserves.

\section{MATERIALS AND METHODS}

Study areas. The study was conducted at 15 no-take reserves and 14 adjacent control (fished) sites in the central Philippines (Table 1, Fig. 1). All reserves were established under local Municipality law. No-take protection has been maintained since the year of establishment. Surveillance and enforcement are carried out by members of the local community (Table 1). However, the Alegre reserve in Sogod, Cebu is maintained by the Alegre Beach Resort, which provides the marker buoys and patrol boats. All no-take reserves are small, ranging in total area from 3.2 ha (approx. $80 \times 400 \mathrm{~m}$ ) at Tawala to $37.5 \mathrm{ha}$ (approx. $500 \times 750 \mathrm{~m}$ ) at Sumilon.

The 13 reserves used to infer rates of recovery from once-only spatial comparisons of abundance of target fish in reserve and control (fished) sites were all coastal reserves, adjacent to large, mainland islands (Fig. 1). These reserves (and their corresponding nonreserves) had a wide variety of slopes and rugosities. Surveys were carried out in fringing coral reefs with a mean hard coral cover of $28 \%$ in reserve sites and $24 \%$ in fished nonreserve sites (Table 1).

The 2 reserves used to measure actual rates of recovery, Sumilon and Apo, were located on small islands 3 and $5 \mathrm{~km}$ offshore from the mainland islands of Cebu and Negros, respectively (Fig. 1). Sumilon Island is a coralline island $\left(0.23 \mathrm{~km}^{2}\right)$, surrounded by a fringing coral reef $\left(0.5 \mathrm{~km}^{2}\right)$ to the $40 \mathrm{~m}$ isobath. Apo Island is a mainland island $\left(0.7 \mathrm{~km}^{2}\right)$, surrounded by $1.06 \mathrm{~km}^{2}$ of fringing coral reef to the $60 \mathrm{~m}$ isobath $\left(0.7 \mathrm{~km}^{2}\right.$ to the $20 \mathrm{~m}$ isobath). The fringing coral reefs of these reserves had steep slopes and high rugosity, with a mean hard coral cover of 34 (Sumilon) and $54 \%$ (Apo) (Table 1). The fished nonreserve sites had lower rugosity, more gradual slopes and lower mean hard coral cover than the reserves (17 and $18 \%$ for Sumilon and Apo, respectively). Russ \& Alcala (2003) provide a detailed description of the reserve and nonreserve sites monitored at Sumilon and Apo.

Table 1. Summary information for the 15 no-take marine reserves studied. Sumilon (2) and Apo (7) reserves and their nonreserve (fished) sites were monitored regularly from 1983 to 2001. Negative years of protection at Sumilon reserve indicate years open to fishing. The other 13 reserves and their nonreserve (fished) sites were surveyed once between June 2002 and April 2003. See Fig. 1 for reserve locations. Live coral: mean percentage of live hard coral cover; Res: reserve; Nres: nonreserve. Rugosity and Steepness indices were estimated on a scale of 0 (low) to 4 (high). SE shown in parentheses

\begin{tabular}{|c|c|c|c|c|c|c|c|c|c|c|}
\hline & \multirow{2}{*}{$\begin{array}{l}\text { No-take } \\
\text { reserve }\end{array}$} & \multirow{2}{*}{$\begin{array}{c}\text { Year } \\
\text { established }\end{array}$} & \multirow{2}{*}{$\begin{array}{l}\text { Years of protection } \\
\text { when surveyed }\end{array}$} & \multirow{2}{*}{$\begin{array}{l}\text { Area } \\
\text { (ha) }\end{array}$} & \multicolumn{2}{|c|}{ Live coral (\%) } & \multicolumn{2}{|c|}{ Rugosity } & \multicolumn{2}{|c|}{ Steepness } \\
\hline & & & & & Res & Nres & Res & Nres & Res & Nres \\
\hline 1 & Alegre & 1991 & 13 & 20 & $46.8(3.4)$ & $37.5(8.0)$ & 3 & 3 & 4 & 4 \\
\hline 2 & Sumilon & 1974 & -3 to 9 & 37.5 & $34.0(2.8)$ & $17.0(1.3)$ & $3.4(0.08)$ & $1.7(0.03)$ & 3 & 2 \\
\hline 3 & Bolisong & 1995 & 7 & 10 & $51.2(6.4)$ & $48.8(5.2)$ & 4 & 3 & 3 & 3 \\
\hline 4 & Tandayag & 1996 & 6 & 6 & $52.8(6.5)$ & $28.2(7.0)$ & 4 & 3 & 2 & 1 \\
\hline 5 & Cangmating & 1997 & 4 & 6 & $14.4(4.9)$ & $18.4(3.9)$ & 2 & 2 & 1 & 1 \\
\hline 6 & Masaplod & 1995 & 6 & 6 & $14.5(5.4)$ & $4.5(4.5)$ & 2 & 1 & 1 & 1 \\
\hline 7 & Apo & 1982 & 1 to 19 & 22.5 & $53.6(2.6)$ & $17.5(2.7)$ & $3.0(0.04)$ & $2.0(0.04)$ & 3 & 1 \\
\hline 8 & Tambobo & 1995 & 7 & 8 & $25.8(1.8)$ & $25.6(6.5)$ & 3 & 3 & 2 & 2 \\
\hline 9 & Bongalonan & 1993 & 9 & 20 & $27.8(2.5)$ & $25.3(3.6)$ & 3 & 3 & 4 & 4 \\
\hline 10 & Canlucani & 2000 & 2 & 9 & $5.9(1.2)$ & $16.6(4.7)$ & 2 & 3 & 1 & 1 \\
\hline 11 & Napo & 2002 & 0.5 & 12.3 & $8.2(1.6)$ & - & 2 & - & 4 & - \\
\hline 12 & Doljo & 1994 & 8 & 7.7 & - & - & 4 & 4 & 3 & 3 \\
\hline 13 & Danao & 1994 & 8 & 8 & - & - & 3 & 3 & 4 & 4 \\
\hline 14 & Tawala & 1994 & 8 & 3.2 & - & - & 3 & 3 & 3 & 3 \\
\hline 15 & Binaliwan & 2000 & 1 & 8.5 & $13.9(4.2)$ & $12.8(3.7)$ & 2 & 2 & 1 & 1 \\
\hline
\end{tabular}


Fish populations. Estimates of density and size structure of all species of Serranidae (Epinephelinae), Lutjanidae and Lethrinidae were made by underwater visual census (UVC) once in 13 different notake marine reserves and at adjacent nonreserve sites in the central Philippines between June 2002 and April 2003 (Fig. 1, Table 1). The same estimates were made 14 times at Sumilon and Apo no-take reserves and nonreserve sites between 1983 and 2001 (Fig. 1, Table 1). At Sumilon reserve, a complex history of management (Russ \& Alcala 1999) allowed 14 measurements of fish biomass at durations of reserve protection ranging from -3 (i.e. fished for $3 \mathrm{yr}$ after reserve status removed) to 9 yr over the period 1983 to 2001. A total of 4 data points collected for the Sumilon Island nonreserve (control) site (1988, 1990, 1991 and 1992) were omitted. During this period, fishing was banned at this site and biomass of predatory fish increased (Russ \& Alcala 1996a, 2003). At Apo reserve, 14 measurements were taken at durations of reserve protection ranging from 1 to 19 yr over the same period. Estimates of fish biomass were made at each reserve in December or November of each year from 1983 to 2001 except for the years 1984, 1986-1987 and 1996. This resulted in 14 measurements of

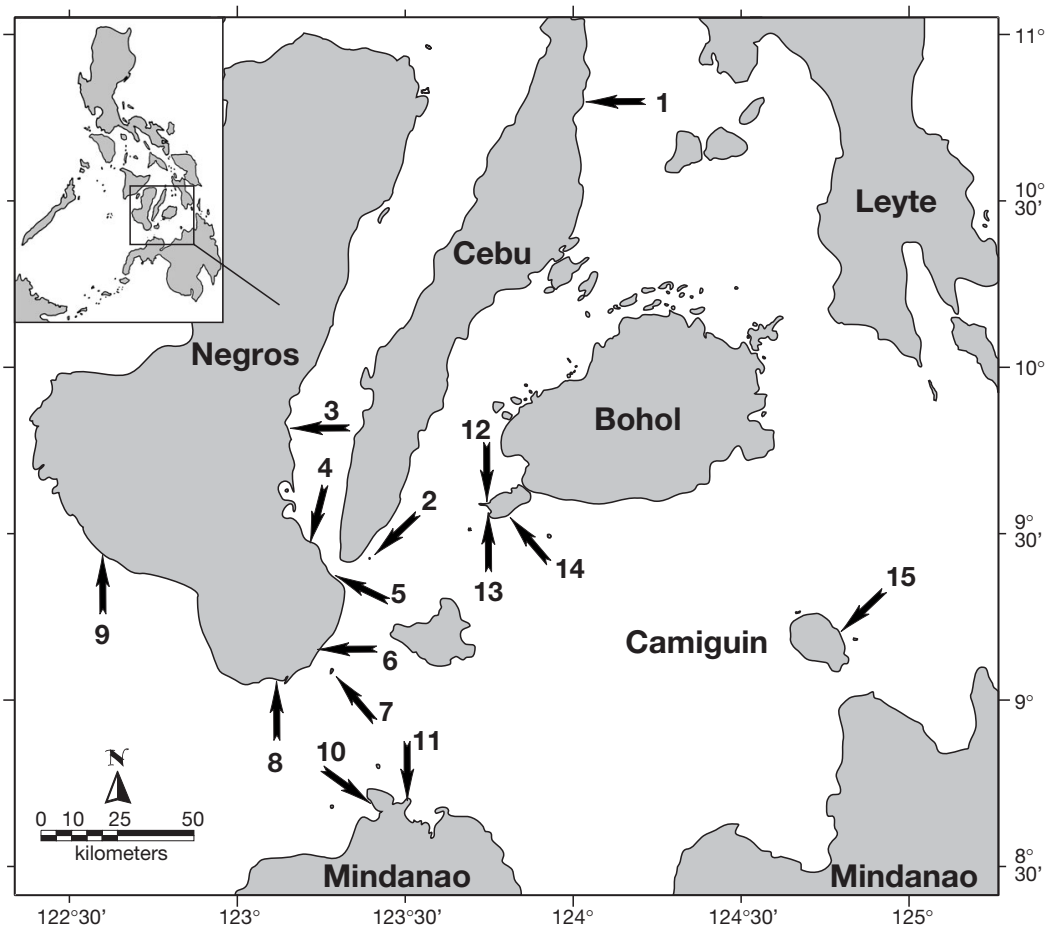

Fig. 1. The southern Philippines showing locations of the 15 no-take marine reserves studied. Names of reserves and their local municipalities are: 1. Alegre, Sogod; 2. Sumilon Island, Oslob; 3. Bolisong, Manjuyod; 4. Tandayag, San Jose; 5. Cangmating, Sibulan; 6. Masaplod, Dauin; 7. Apo Island, Dauin; 8. Tambobo, Siaton; 9. Bongalonan, Basay; 10. Canlucani, Dapitan; 11. Napo, Dapitan; 12. Doljo, Panglao; 13. Danao, Panglao; 14. Tawala, Panglao; 15. Binaliwan, Mahinog. Details of all reserves are given in Table 1. Long-term monitoring was carried out at Sumilon (2) and Apo (7) islands biomass over the period 1983 to 2001.

For the 13 reserve and 12 nonreserve sites surveyed once, 3 replicate transects $(50 \times 10 \mathrm{~m}), 10$ to $20 \mathrm{~m}$ apart, were placed parallel to the reef crest at depths of 10 to $12 \mathrm{~m}$ (deep transects) and 2 to $3 \mathrm{~m}$ (shallow transects). Six replicates ( 3 deep, 3 shallow, pooled over depths for this study), were made inside the marine reserve and at a nonreserve site $250 \mathrm{~m}$ from the boundary of the marine reserve. Censuses were carried out by a single observer (B. Stockwell) at these sites.

At Sumilon and Apo islands, censuses were carried out by 1 observer (G. R. Russ) at 6 replicate $(50 \times 20 \mathrm{~m})$ plots on the reef slopes of each reserve ( 3 to $17 \mathrm{~m}$ Sumilon, 5 to $17 \mathrm{~m} \mathrm{Apo}$ ) and nonreserve (9 to $17 \mathrm{~m}$ at both islands) in December or November of 1983, 1985, 1988, 1990 to 1995 and 1997 to 2001. Fish were counted at the same replicate locations each year. The small size of the reserves, combined with accurate maps of features on the coast, buoy sites and underwater features, permitted placement of each replicate to within \pm 5 to $10 \mathrm{~m}$ of its previous position each year; 6 replicate censuses were made at each site, each separated by a distance of approximately $10 \mathrm{~m}$. For all sites and times at all reserves, counts and size structure estimates of all species were made on replicate transects or plots, with sizes of fish estimated to $\pm 5 \mathrm{~cm}$ TL $( \pm 2 \mathrm{~cm}$ for Serranidae at Sumilon and Apo). Biomass was computed from density and size structure using known length-weight relationships (Froese \& Pauly 2003). More narrow transects were used in the spatial comparisons $(10 \mathrm{~m})$ than in the temporal monitoring $(20 \mathrm{~m})$, because the sites compared once only were close to mainland coasts and generally had lower water visibility than offshore islands where temporal monitoring occurred. Nevertheless, observers made full searches of the transect areas, irrespective of the transect size.

Habitat complexity. Hard coral cover, rugosity (structural complexity of the benthic substratum) and steepness of the reef slope were estimated for most sites and some times. Hard coral cover was estimated using the line intercept method (LIT). At 10 of 13 locations surveyed once only (Danao, Doljo and Tawala reserve and nonreserves, and the Napo nonreserve excluded [see Table 1]) a $20 \mathrm{~m}$ LIT was completed (by B. Stockwell) at each of the 6 replicate transects used 
to survey fish. Presence or absence of growth forms of hard coral (English et al. 1997) were recorded every $20 \mathrm{~cm}$ along the $20 \mathrm{~m}$ line, giving 100 records per LIT. These records were used to calculate the percentage cover of hard corals at each UVC fish transect. At Sumilon and Apo islands where long-term monitoring took place (Table 1), hard coral cover was estimated for the period 1983 to 1999 by LIT. Nine (reserve) and 6 (nonreserve) replicate $20 \mathrm{~m}$ line intercept transects (as described above) were taken on the shallow reef slopes (4 to $7 \mathrm{~m}$, Sumilon and Apo Reserves, 9 to $12 \mathrm{~m}$ at the nonreserve sites) in the same areas where the UVC for fish were made. LIT estimates of hard coral cover were made at most sampling times at Sumilon reserve (except 1988), Sumilon nonreserve (except 1988 to 1992), and Apo reserve (except 1988 to 1992) and Apo nonreserve (except 1985 to 1992). An exception to the use of the LIT method for estimating coral cover was made at Sumilon and Apo islands between 1999 and 2001. In these years, each plot $(50 \times 20 \mathrm{~m}, \mathrm{n}=$ 6) used to survey fish at each reserve and nonreserve site was divided into 10 quadrats $(10 \times 10 \mathrm{~m})$. The percentage cover of all benthic substrata, including hard corals, was estimated by eye (in units of $5 \%$ ) for each quadrat. The average of the 10 quadrats was taken as the percentage cover over the entire plot.

For spatial comparisons (except the Napo nonreserve, see Table 1) the diver also scored the rugosity of the reef substratum-0 (least rugose) to 4 (most rugose) - and the steepness of the reef slope - 0 (horizontal) to 4 (vertical) — visually for every site (Table 1). Detailed estimates of rugosity and steepness of slope were not made at Sumilon and Apo islands until 1999. In 1999, 2000 and 2001 estimates of benthic cover, rugosity and steepness of slope were made visually in each of 10 quadrats $(10 \times 10 \mathrm{~m})$ within each of the 6 plots $(50 \times 20 \mathrm{~m})$ used to survey fish in reserve and nonreserve sites. Rugosity and steepness of slope were scored on the same scales (0 to 4) as those used for spatial comparisons. Steepness of slope was constant over the study period (1983 to 2001) at all sites. To estimate rugosity at Sumilon and Apo before 1999, we used the detailed data collected in 1999 to 2001 at all Sumilon and Apo sites to calculate a predictive relationship between the percentage cover of sand + rubble + bare substratum and the rugosity index. This relationship was highly significant (Rugosity $=-0.02 \times$ ( $\%$ cover sand + rubble + bare substratum $)+3.53 ; \mathrm{r}^{2}=$ $\left.0.28, F_{1,234}=90.26, \mathrm{p}<0.001\right)$. A comparison of sitespecific predicted and observed rugosity estimates at Sumilon and Apo for 1999 to 2001 indicated that a site-specific correction factor had to be applied to this predictive relationship to prevent underestimation of rugosity at Sumilon reserve (by 0.71) and Apo reserve (by 0.16 ) and overestimation of rugosity at Sumilon nonreserve (by 0.40) and Apo nonreserve (by 0.61). This predictive relationship, with its site-specific correction factor, was used to predict rugosity at the Sumilon and Apo sites for sample times before 1999.

Statistical analyses. Description of the benthic habitat for each site and time was estimated as a single habitat complexity index (HCI) (R. A. Abesamis, G. R. Russ, A. C. Alcala unpubl.): $\mathrm{HCI}=$ (proportion of live hard coral cover +1$) \times($ mean rugosity +1$) \times($ mean reef steepness +1 ). This index ranges from 1 to 50 . Higher values indicate steeper reef faces with high hard coral cover and rugosity. Lower values indicate relatively flat expanses of sand, rubble, or rock, with low hard coral cover.

Mean biomass $\left(\mathrm{g} \mathrm{m}^{-2}\right.$ ) of fish was plotted against years of reserve protection for both reserve and nonreserve sites surveyed once (13 reserves and 12 nonreserves) and surveyed over the period 1983 to 2001 (Sumilon, Apo). Fish biomass in the nonreserve sites was plotted against 'years of reserve protection at the island' by simply plotting the nonreserve biomass for the same year as that for the biomass estimate in the reserve, for any given duration of protection. Best fit linear (nonreserves) or exponential (reserves) models were fitted to the mean biomass versus years of reserve protection plots. Statistical comparisons of biomass of fish at the reserve and nonreserve sites at the 9 locations with $\mathrm{HCI}$ estimates at reserve and nonreserve sites were made with a univariate 2-factor ANOVA and ANCOVA. The 2 factors in these analyses were a fixed factor 'reserve status' (2 levels) and a random factor 'duration of protection' (9 levels ranging from 1 to $13 \mathrm{yr}$ ). The latter factor was treated as random, since duration of protection equated to location of the 9 reserves and their nonreserve sites. The co-variate in the ANCOVA was the HCI. Fish biomass and HCI data were $\log 10(x+1)$ transformed. Statistical comparisons of biomass of fish at the reserve and nonreserve sites over the 9 times (Apo) or 10 times (Sumilon) that also had HCI estimates were made separately for each island using univariate, repeated measures ANOVA and ANCOVA. The 3 factors in these analyses were 'reserve status' (2 levels), 'plots' (6 levels) nested within each reserve and nonreserve site (a random factor), and the repeated measure 'time' with either 9 (Apo) or 10 (Sumilon) levels. The co-variate in the ANCOVA was the HCI. Fish biomass and HCI data were $\log 10(x+1)$ transformed. We used GreenhouseGeisser adjusted p-values in the repeated measures ANOVAs (Statistica 1995). For all ANOVAs and ANCOVAs, the data were examined for homogeneity of variance (Cochran's test, $\mathrm{p}<0.05$; Underwood 1981), skewness and outliers (box plots), normality, and correlations between means and variances. We used Tukey's test to compare means after ANOVAs. 
Linear regressions were used to describe the relationship between the HCI and years of reserve protection for the 9 reserve and 9 nonreserve sites used in spatial comparisons for which data were available. Linear regressions were used also to describe this relationship for the Sumilon and Apo reserve and nonreserve sites over time. Slopes of these regressions, if significant, were compared for reserve and nonreserve sites by $t$-tests.

A reserve effect index was calculated as $\log 10$ (Reserve biomass +1 / Nonreserve biomass +1 ). Linear regressions were used to describe the relationship between this index and years of reserve protection for the 12 reserves used in spatial comparisons for which data were available. Linear regressions were used also to describe this relationship for Sumilon and Apo reserves over time. Slopes of these regressions, if significant, were compared by $t$-tests.

\section{RESULTS}

A highly significant interaction in the ANOVA was detected between reserve status and duration of reserve protection for once-only spatial comparisons (Table 2, Fig. 2). This interaction remained significant when the effect of the HCI was taken into account in the ANCOVA (Table 2, Fig. 3). In addition, the effect of reserve status and duration of reserve protection were significant in both the ANOVA and the ANCOVA (Table 2). The relationship between biomass of large predatory fish and duration of protection was best described as exponential for reserves (Fig. 2, Table 3) and as linear for nonreserves (Fig. 2, Table 3). The first significant difference between reserve and nonreserve biomass in the ANOVA was detected for reserves protected for 6 yr (Tukey's test, p < 0.05; Fig. 2).
A significant interaction in the repeated measures ANOVA was detected between reserve status and duration of reserve protection for temporal monitoring at both Sumilon and Apo Islands (Fig. 2, Table 2). This interaction was even more significant when the effect of the HCI was taken into account (Table 2, Fig. 3). The effect of duration of reserve protection was significant in both the ANOVA and the ANCOVA (Table 2). In contrast to the result for spatial comparisons, the effect of reserve status was significant for the repeated measures ANOVA but not for the repeated measures ANCOVA at both Sumilon and Apo islands (Table 2). The relationship between biomass of large predatory fish and duration of protection was best described as exponential for reserves and linear for nonreserves (Fig. 2, Table 3). The first significant difference between reserve and nonreserve biomass in the ANOVA was detected for durations of reserve protection of 4 and $3 \mathrm{yr}$ for Sumilon and Apo, respectively (Tukey's test, p < 0.05; Fig. 2).

The ratio of reserve/nonreserve biomass of large predatory fish at the maximum observed duration of reserve protection was similar for rates inferred from spatial comparisons and estimates measured by temporal monitoring. Spatial comparisons suggest a ratio of 9.0 after $13 \mathrm{yr}$ of reserve protection; temporal monitoring indicates a ratio of 9.8 after $9 \mathrm{yr}$ of reserve protection at Sumilon, and 6.3 after $19 \mathrm{yr}$ of reserve protection at Apo.

Differences in the HCI in space and over time could potentially confound inferences and measurements of the effects of no-take marine reserves on biomass of large predatory fish. In the ANCOVA comparing fish biomass between reserve and nonreserve sites once only (the spatial comparisons), the effect of the HCI covariate was not significant (Table 2). Relationships

Table 2. Summary of ANOVAs and ANCOVAs for once-only spatial comparisons of 9 reserve and 9 nonreserve sites, and for temporal monitoring (1983 to 2001) of reserve and nonreserve sites at Sumilon and Apo islands. The variate in all analyses is biomass of large predatory fish. The co-variate is a habitat complexity index. DOP is duration of protection. ns: not significant $(p>0.05) ;{ }^{*} p<0.05 i^{* *} p<0.01 i^{* * *} p<0.001$

\begin{tabular}{|c|c|c|c|c|c|c|}
\hline & Source & $\begin{array}{l}\text { OVA } \\
\qquad F(\mathrm{df})\end{array}$ & $\overline{\mathrm{p}}$ & Source & $\begin{array}{l}\text { COVA } \\
\qquad F(\mathrm{df})\end{array}$ & $\mathrm{p}$ \\
\hline Spatial data & $\begin{array}{l}\text { Reserve } \\
\text { DOP } \\
\text { Reserve } \times \text { DOP }\end{array}$ & $\begin{array}{r}17.85(1,8) \\
9.67(8,90) \\
4.81(8,90)\end{array}$ & $\begin{array}{l}* * \\
* * * \\
* * *\end{array}$ & $\begin{array}{l}\text { Reserve } \\
\text { DOP } \\
\text { Reserve } \times \text { DOP } \\
\text { Co-variate }\end{array}$ & $\begin{array}{l}9.85(1,8) \\
7.69(8,89) \\
4.26(8,89) \\
1.72(1,89)\end{array}$ & $\begin{array}{l}{ }^{*} \\
* * * \\
* * * \\
\text { ns }\end{array}$ \\
\hline Sumilon & $\begin{array}{l}\text { Reserve } \\
\text { DOP } \\
\text { Reserve } \times \text { DOP } \\
\text { Plots }\end{array}$ & $\begin{array}{r}41.22(1,10) \\
7.33(9,90) \\
10.18(9,90) \\
2.74(10,90)\end{array}$ & $\begin{array}{l}* * * \\
* * * \\
* * * \\
* *\end{array}$ & $\begin{array}{l}\text { Reserve } \\
\text { DOP } \\
\text { Reserve } \times \text { DOP } \\
\text { Plots } \\
\text { Co-variate }\end{array}$ & $\begin{array}{c}1.48(1,9) \\
11.88(9,81) \\
11.71(9,81) \\
16.42(9,81) \\
8.98(10,81)\end{array}$ & $\begin{array}{l}\mathrm{nS} \\
* * * \\
* * * \\
* * * \\
* * *\end{array}$ \\
\hline Apo & $\begin{array}{l}\text { Reserve } \\
\text { DOP } \\
\text { Reserve } \times \text { DOP } \\
\text { Plots }\end{array}$ & $\begin{array}{c}38.06(1,10) \\
10.05(8,80) \\
2.72(8,80) \\
5.07(10,80)\end{array}$ & $\begin{array}{c}* * * \\
* * * \\
* \\
* *\end{array}$ & $\begin{array}{l}\text { Reserve } \\
\text { DOP } \\
\text { Reserve } \times \text { DOP } \\
\text { Plots } \\
\text { Co-variate }\end{array}$ & $\begin{array}{r}0.26(1,9) \\
9.32(8,72) \\
11.93(8,72) \\
35.61(9,72) \\
5.02(9,72)\end{array}$ & $\begin{array}{l}\mathrm{nS} \\
* * * \\
* * * \\
* * * \\
* * *\end{array}$ \\
\hline
\end{tabular}



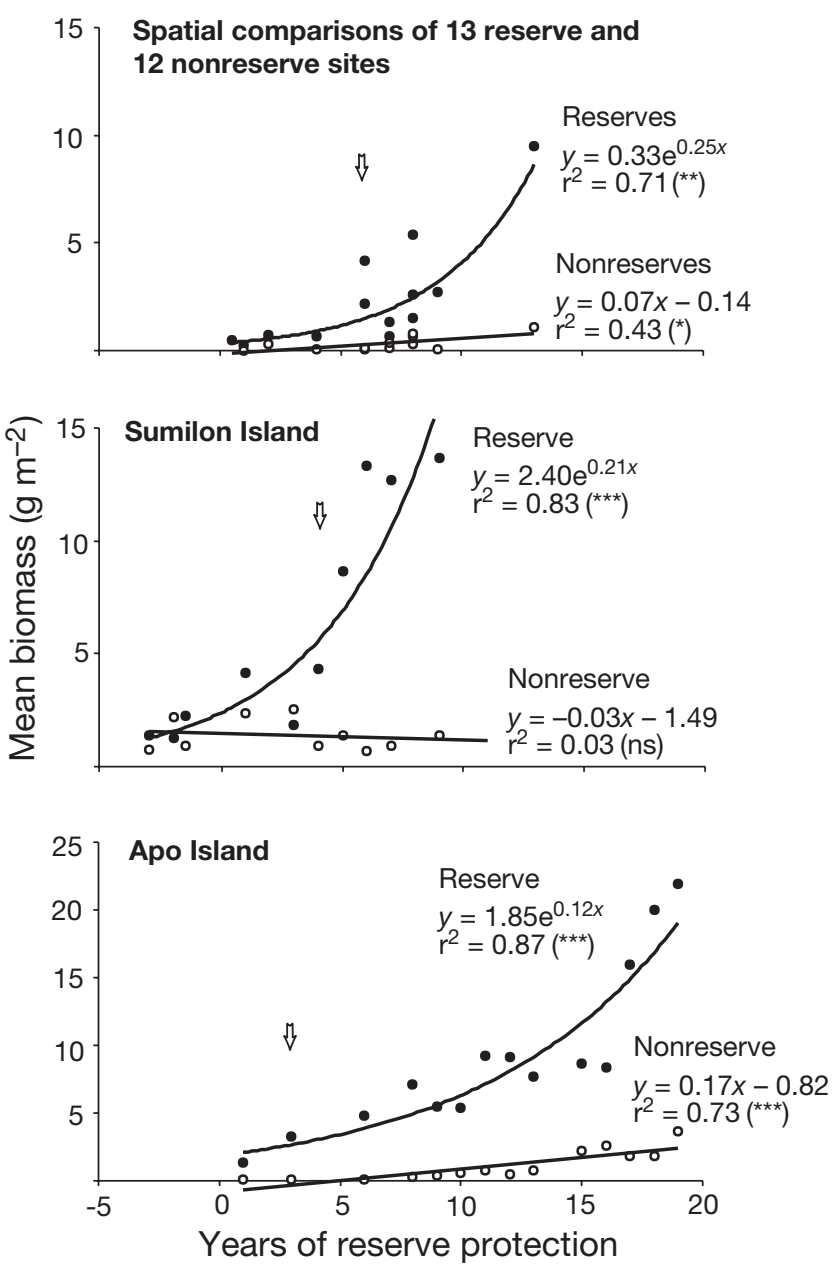

Fig. 2. Mean biomass $\left(\mathrm{g} \mathrm{m}^{-2}\right)$ of large predatory reef fish plotted against duration of reserve protection (yr). Top: 13 no-take reserves of varying age ( 0.5 to $13 \mathrm{yr}$ ) and 12 nearby nonreserve (fished) sites each sampled once. Middle and bottom: temporal monitoring (1983 to 2001) at Sumilon and Apo islands, respectively. Exponential and linear models fitted to reserve and nonreserve data, respectively. Negative years of protection at Sumilon indicate years open to fishing. Vertical arrows indicate duration at first significant difference between reserve and nonreserve biomass (Tukey's test, 0.05 significance level). •: reserve; $\bigcirc$ : nonreserve. ns: not significant $(\mathrm{p}>0.05) ;{ }^{*} \mathrm{p}<0.05 ;{ }^{* *} \mathrm{p}<0.01 ;{ }^{* * *} \mathrm{p}<0.001$

between biomass of large predatory fish and the HCI in the spatial comparison data were not significant at both reserve and nonreserve sites (Table 3). The relationship between $\mathrm{HCI}$ and duration of protection in the spatial comparisons was highly significant for both reserves and nonreserves (Table 3, Fig. 3). However, the slopes of these regressions did not differ significantly $\left(t_{14 \mathrm{df}}=0.70, \mathrm{p}>0.2\right)$.

In the repeated measures ANCOVAs of the temporal monitoring data at Sumilon and Apo, the HCI covariate had a significant effect on biomass of large predatory fish (Table 2). This was due mainly to large

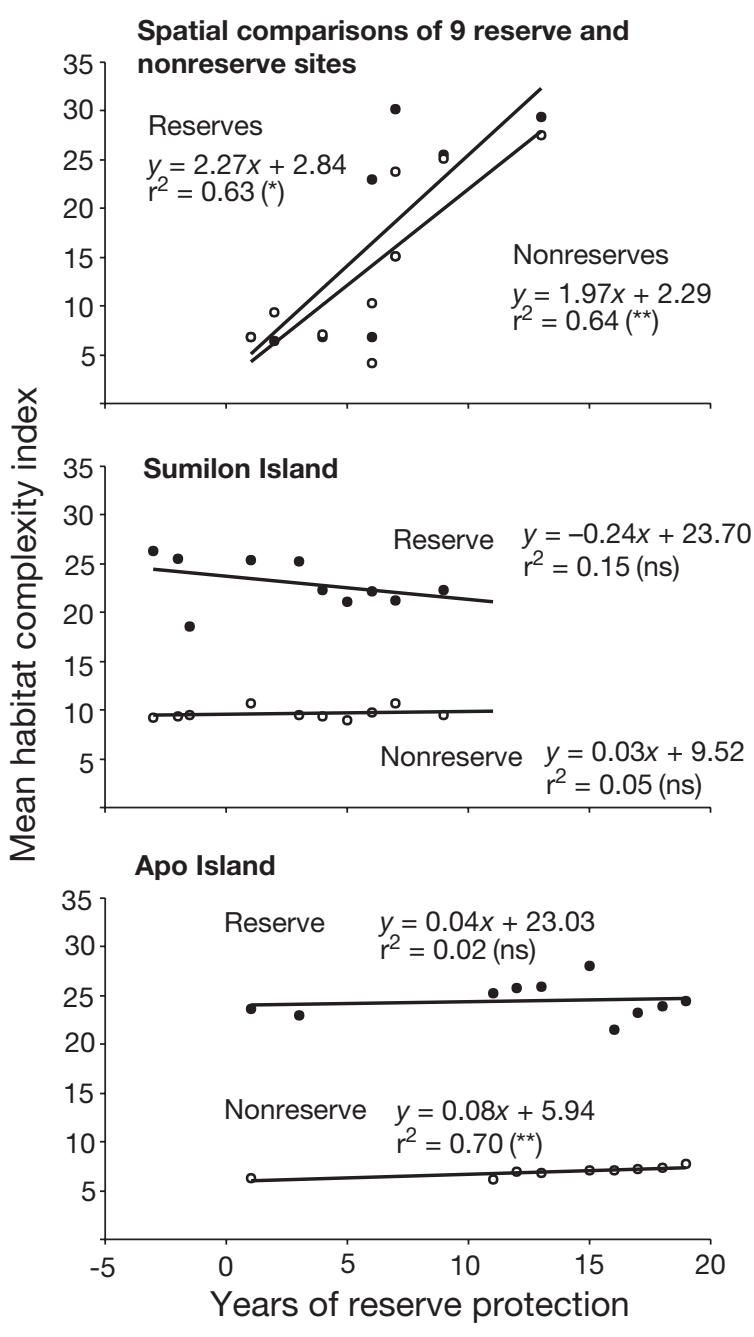

Fig. 3. Mean habitat complexity index-(proportion of live hard coral cover +1$) \times($ mean rugosity +1$) \times($ mean reef steepness +1 ) - plotted against duration of reserve protection (yr). Top: 9 no-take reserves of varying age ( 2 to $13 \mathrm{yr}$ ) and 9 nearby nonreserve (fished) sites each sampled once. Middle and bottom: temporal monitoring (1983 to 2001) at Sumilon and Apo islands, respectively. Negative years of protection at Sumilon indicate years open to fishing. -: reserve; $\bigcirc$ : nonreserve. Significance levels of regressions as in Fig. 2

differences in the HCI between reserve and nonreserve sites at both islands (Fig. 3). Reserves had much higher HCIs than the nonreserves at each island (Fig. 3), and fish biomass built up strongly in reserves but not in nonreserves as duration of protection of reserves increased (Fig. 2). However, the HCIs did not change significantly with duration of protection at Sumilon and Apo reserves, nor at the Sumilon nonreserve (Fig. 3, Table 3). At Apo nonreserve, the relationship between HCI and duration of protection was significant (Fig. 3, Table 3). Furthermore, there were no significant relationships between biomass of large 
Table 3. Summary of regression statistics for once-only spatial comparisons of 13 reserve and 12 nonreserve sites, and for temporal monitoring (1983 to 2001) of reserve and nonreserve sites at Sumilon and Apo islands. All regressions were linear except for fits of biomass of large predatory reef fish versus years of reserve protection in reserves, which were exponential (+). HCI: habitat complexity index; REI: reserve effect index; SP: once-only spatial comparison; SPR: spatial comparison reserves; SPNR: spatial comparison nonreserves; AR: Apo reserve; ANR: Apo nonreserve; SR: Sumilon reserve; SNR: Sumilon nonreserve; S: Sumilon Island; A: Apo island. See Table 2 for $p$-values

\begin{tabular}{|llccc|}
\hline Regression & Site & $\mathrm{r}^{2}$ & $F(\mathrm{df})$ & $\mathrm{p}$ \\
\hline Fish biomass vs. & SPR $(+)$ & 0.71 & $22.10(1,11)$ & ${ }^{* *}$ \\
Years of protection & SPNR & 0.43 & $7.47(1,10)$ & ${ }^{*}$ \\
& SR $(+)$ & 0.83 & $45.81(1,8)$ & ${ }^{* * *}$ \\
& SNR & 0.03 & $0.25(1,8)$ & $\mathrm{ns}$ \\
& AR $(+)$ & 0.87 & $81.93(1,12)$ & ${ }^{* * *}$ \\
& ANR & 0.73 & $31.79(1,12)$ & ${ }^{* * *}$ \\
HCI vs. & SPR & 0.63 & $11.66(1,7)$ & ${ }^{*}$ \\
Years of protection & SPNR & 0.64 & $12.68(1,7)$ & ${ }^{* *}$ \\
& SR & 0.15 & $1.45(1,8)$ & $\mathrm{ns}$ \\
& SNR & 0.05 & $0.41(1,8)$ & $\mathrm{ns}$ \\
& AR & 0.02 & $0.12(1,8)$ & $\mathrm{ns}$ \\
Fish biomass vs. HCI & ANR & 0.70 & $15.96(1,7)$ & ${ }^{* *}$ \\
& SPR & 0.21 & $1.88(1,7)$ & $\mathrm{ns}$ \\
& SPNR & 0.30 & $2.94(1,7)$ & $\mathrm{ns}$ \\
& SR & 0.20 & $1.94(1,8)$ & $\mathrm{ns}$ \\
& SNR & 0.01 & $0.08(1,8)$ & $\mathrm{ns}$ \\
& AR & 0.01 & $0.01(1,8)$ & $\mathrm{ns}$ \\
& ANR & 0.72 & $17.90(1,7)$ & ${ }^{* *}$ \\
& SP & 0.41 & $7.06(1,10)$ & ${ }^{*}$ \\
REI vs. & S & 0.67 & $15.90(1,8)$ & ${ }^{* *}$ \\
Years of protection & A & 0.11 & $1.41(1,12)$ & $\mathrm{ns}$ \\
& & & & \\
\hline
\end{tabular}

predatory fish and the HCI at Sumilon Reserve, Sumilon nonreserve, and Apo reserve (Table 3). At Apo nonreserve there was a significant relationship between biomass of large predatory fish and $\mathrm{HCI}$ (Table 3). Overall, HCI did not confound estimates of reserve effects significantly in either spatial comparisons or temporal monitoring. This was due mainly to the fact that the slopes of the HCI versus duration of protection plots did not differ significantly or substantially between reserve and nonreserve sites for both spatial comparisons and temporal monitoring (Fig. 3).

The relationship between the reserve effect index and duration of reserve protection was significant for spatial comparisons, despite considerable variation in the magnitude of the index for reserves with 6 to $9 \mathrm{yr}$ of protection (Fig. 4, Table 3). The latter variation likely reflects high variation in the HCI at reserve sites protected for 6 to $7 \mathrm{yr}$ and their respective nonreserve sites (Fig. 3). The relationship between the reserve effect index and duration of reserve protection was also significant for temporal monitoring at Sumilon (Fig. 4, Table 3) but not for temporal monitoring at Apo (Fig. 4, Table 3). The slope of the relationship derived from
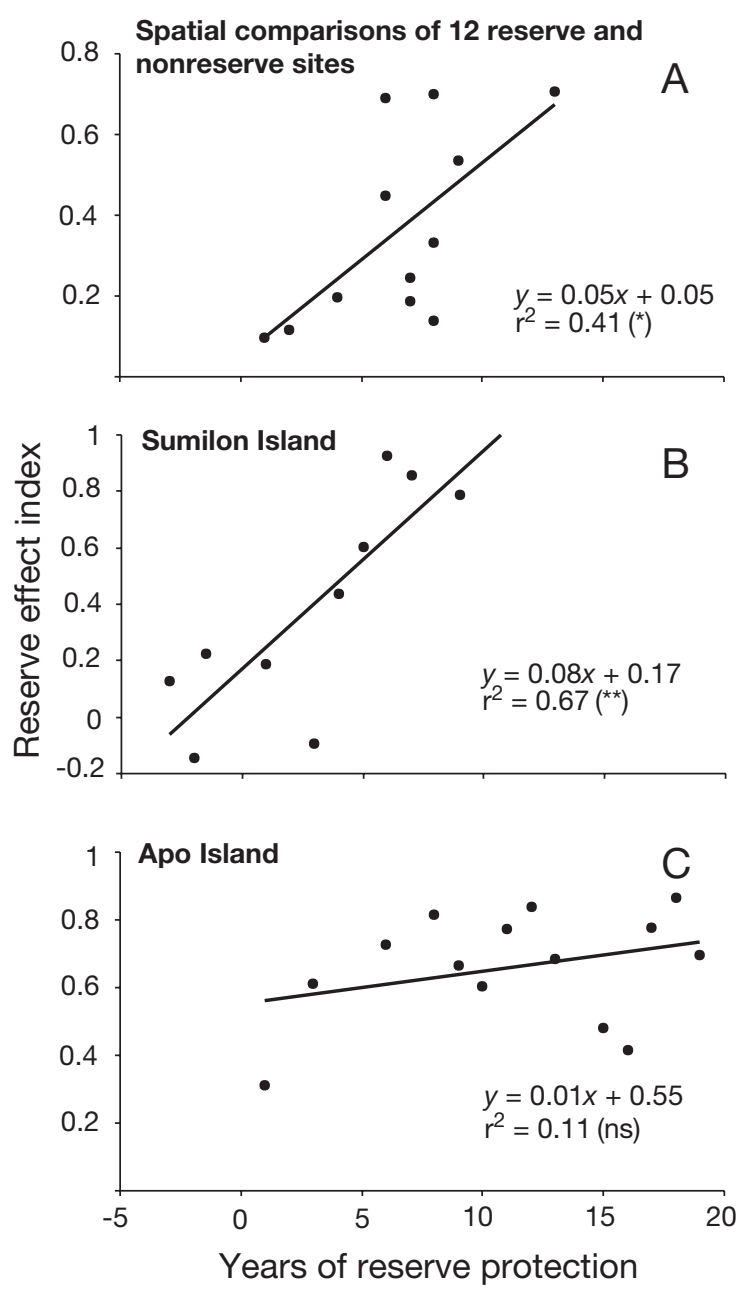

Fig. 4. Mean reserve effect index-log 10 (Reserve biomass +1 / Nonreserve biomass +1 ) - plotted against duration of reserve protection (yr). (A) 12 no-take reserves of varying age (1 to $13 \mathrm{yr}$ ) and 12 nearby nonreserve (fished) sites each sampled once. (B,C) Temporal monitoring (1983 to 2001) at Sumilon and Apo islands, respectively. Negative years of protection at Sumilon indicate years open to fishing. Significance levels of regressions as in Fig. 2

spatial comparisons did not differ significantly from that obtained by temporal monitoring at Sumilon $\left(t_{18 \mathrm{df}}=0.45, \mathrm{p}>0.5\right)$ (Fig. 4), but clearly differed from that obtained by temporal monitoring at Apo Island (Fig. 4, Table 3).

\section{DISCUSSION}

The general implication of this study is that one can make useful inferences about rates of recovery in notake marine reserves of different ages from once-only spatial comparisons of reserve and fished sites, provided that such inferences are derived from carefully designed studies. Clearly, the target organisms, the 
methods and effectiveness of reserve protection, and the methods of census, need to be similar. Furthermore, the habitats in the reserve and fished sites need to be as similar as possible, and/or habitat differences between reserve and fished sites need to be accounted for in analyses. In terms of statistical independence of data points through time, it could be argued that the once-only spatial comparison approach is superior to monitoring over time at the same sites. Such an approach assumes identical environmental conditions and history at each reserve and control, or has to account for such differences, if they are known. Pragmatically, once-only spatial comparisons of reserve and fished sites are not an adequate substitute for properly designed Before After Control Impact Pair (BACIP) experiments on reserves that incorporate long-term monitoring (Jones et al. 1993, Edgar \& Barrett 1997, 1999, Mosquera et al. 2000, Polunin 2002, Russ 2002, Willis et al. 2003a). The recovery process in reserves is complex, influenced by a wide range of factors (Jennings 2001). Monitoring studies allow not only detection of change through time, but determination of mechanisms of change (e.g. in rates of recruitment, mortality or growth) as well. Thus, spatial comparisons might merely provide a rapid, but approximate, inference about rates of recovery.

The specific implication of this study is that results of long-term, intensive monitoring of 2 reserves, Sumilon and Apo (e.g. Russ \& Alcala 1996a, 2003), may have spatial generality across a broad region of the southern Philippines. That is, the positive long-term effects of no-take reserve protection at Sumilon and Apo Islands on biomass of fish targeted by fisheries are likely to be developing at many other reserves in the southern Philippines.

There was a remarkable consistency of the relationship between biomass of large predatory reef fish and duration of reserve protection in this study, for both spatial comparison and temporal monitoring data (Fig. 2). These results were obtained despite (1) differences in observers, (2) minor differences in transect sizes, and (3) the reserves at the 2 temporal monitoring sites being slightly larger than those used for spatial comparisons, and located on offshore islands (Table 1). This consistency of results suggests that none of these potentially confounding effects introduced any major biases in the study. Biomass of these fishes was rising exponentially inside reserves at Sumilon and Apo Islands, and was inferred to be doing so in 13 other reserves in the southern Philippines. In fished areas outside the reserves, biomass remained relatively low over considerable periods of real or inferred time (Fig. 2). The duration of protection required to detect significantly higher reserve biomass was similar but lower for temporal monitoring (3 to $4 \mathrm{yr}$ ) than for spatial comparisons (6 yr). Furthermore, the reserve/ nonreserve biomass ratios at maximum duration of reserve protection were similar for inferred (9.0 for $13 \mathrm{yr}$ of protection) and measured (6.3 for $19 \mathrm{yr}$ of protection at Apo; 9.8 for $9 \mathrm{yr}$ of protection at Sumilon) estimates. However, there is insufficient replication in this study to determine whether the results have broader generality. The patterns of biomass recovery in reserves were clearly, in the case of temporal monitoring, and likely, in the case of spatial comparisons, due to the effects of no-take reserve protection.

The habitat complexity was greater in the reserve than in the nonreserve site at both Sumilon and Apo Islands (Fig. 3). The fact that the 'reserve status' factor changed from significant to nonsignificant when the effect of habitat was accounted for in the repeated measures ANCOVA indicates that habitat complexity did affect biomass of large predatory reef fish significantly. However, the HCIs changed little over time at either Sumilon or Apo Islands (Fig. 3). Clearly, habitat complexity did not co-vary with fish biomass, which increased markedly in the reserves, but stayed relatively stable in the fished sites (Fig. 2). A result of some interest was the significant positive relationship between the HCI and duration of protection for both reserve and nonreserve (fished) sites used in the spatial comparisons (Fig. 3). In this case, habitat complexity differed little between paired reserve and nonreserve sites, since the data and the fitted lines are close together in Fig. 3. Thus the effect of reserve status remained significant, even when the effect of habitat was accounted for in the ANCOVA. As for the temporal monitoring, habitat complexity did not co-vary with fish biomass, which was inferred to increase markedly in the reserves, but stay relatively stable in the fished sites (Fig. 2). Clearly, the increase in habitat complexity with duration of reserve protection in the spatial comparison data of Fig. 3 does not indicate, in this case, that the longer a site is protected, the better the habitat becomes. An improvement in benthic habitat with duration of no-take reserve protection may be a reasonable expectation in some situations (Rodwell et al. 2003). Habitat improvement may even potentially enhance fish biomass inside reserves, and fish yields adjacent to reserves (Rodwell et al. 2003). In the present study, it is likely that the reserves with some of the longest durations of protection (Alegre, Bongalonan, Bolisong, Tandayag) happened also to have some of the best habitat, both inside and adjacent to the reserves (Table 1). Our results may also suggest that reserves being established in the southern Philippines 6 to 13 yr ago may have been more likely to be placed in areas of complex reef habitat (greater slope, rugosity, hard coral cover) than those established more recently. 
This is the first study to use once-only spatial comparisons of abundance of targeted organisms inside and outside no-take marine reserves to demonstrate a significant positive relationship between a reserve effect index (abundance in reserve/abundance outside reserve) and duration of reserve protection (Fig. 4). The high variation in the magnitude of the effect index for reserves protected for 6 to $9 \mathrm{yr}$ (Fig. 4A) suggests that meta-analyses of such spatial comparison data should still be treated with some caution. The slope of this relationship for spatial comparisons did not differ significantly from that derived from temporal monitoring at Sumilon Island (Fig. 4). The slope of the relationship at Apo Island was not significantly different from 0 (Fig. 4).

The result from temporal monitoring at Apo is similar to those obtained by Côté et al. (2001), Halpern \& Warner (2002) and Russ (2002) from spatial comparison data. The lack of a significant positive slope for Apo in Fig. 4 is partially due to a rapid increase in biomass in the reserve, compared to the nonreserve, between the first and third years of protection. In this sense, this result is consistent with the general suggestion made by Halpern \& Warner (2002) of a rapid response. Note, however, that the result for Apo has been measured; the Halpern \& Warner (2002) result has been inferred. Biomass in the Apo reserve did not stabilize after this initial rapid increase, but continued to increase exponentially in the reserve (but not at the fished site) over the next $14 \mathrm{yr}$, i.e. after 6 to $19 \mathrm{yr}$ of protection) (Fig. 2). The log scale on the $y$-axis of Fig. 4 tends to de-emphasize the change in ratio over time. More importantly, the biomass in the Apo nonreserve site actually increased significantly, but linearly, over time (Fig. 2). Thus, the ratio of reserve to nonreserve biomass did not rise as quickly with duration of reserve protection as at Sumilon. This gradual increase in fish biomass at the Apo nonreserve site was related to the concomitant, but very moderate, increase in habitat complexity (Table 3, Fig. 3). The gradual increase in fish biomass at Apo nonreserve may have also been due, at least partially, to spillover from the reserve affecting areas within 200 to $300 \mathrm{~m}$ of the southern boundary of the reserve (Russ \& Alcala 1996b, Russ et al. 2003, 2004). Thus, the lack of a significant positive relationship between the reserve effect index and duration of reserve protection may have been partially due to a lack of independence between the reserve and nonreserve sites at Apo. In fact, Russ \& Alcala (1996b) hypothesized a parabolic relationship between a reserve effect index (reserve biomass/nonreserve biomass) and duration of reserve protection for large predatory reef fish at Apo over the first decade of reserve protection.

The conclusion from this study, that one can make useful inferences about rates of recovery in no-take marine reserves from once-only spatial comparisons of reserve and fished sites, indicates that Russ (2002) was incorrect in suggesting that such an approach lacked utility. However, the caveat placed on our conclusion in the present paper is that inferences must be derived from carefully designed studies. In the present study, we had similar methods of reserve protection and census on the same target group in similar areas. Habitat did not co-vary with reserve status over real or inferred time (Figs. 2 \& 3). Furthermore, since we have been involved in setting up the community-based protection of most of the reserves in this study, we are reasonably confident that the levels of protection have been adequate.

In contrast, the studies of Côté et al. (2001), Russ (2002) and Halpern \& Warner (2002) based their conclusions on an analysis of disparate studies. Many of these disparate studies were confounded by initial choice of reserve site, by habitat differences between reserve and fished sites, and probably most importantly, by differential poaching histories of the reserves. The Côté et al. (2001) and Halpern \& Warner (2002) analyses were also confounded by pooling a variety of life history types (and thus different potential rates of recovery). Ignoring poaching history very likely influenced the non-significant relationship between reserve effect index and age of reserve considerably in the Côté et al. (2001), Halpern \& Warner (2002) and Russ (2002) analyses. However, Côté et al. (2001) and Russ (2002) both concluded that such analyses revealed little about rates of reserve effects. In contrast, Halpern \& Warner (2002) concluded that higher average values of abundance and diversity measures in reserves reached mean levels in a short ( 1 to 3 yr) period, and that values were subsequently consistent across reserves of all ages (up to $40 \mathrm{yr}$ ). Many authors have since questioned the suggestion that most of the recovery occurs early in the life of a reserve (Gell \& Roberts 2002, Denny et al. 2004, Russ \& Alcala 2004, Edgar et al. 2005).

A limitation of our study is that we examine rates of recovery of a group of organisms (cf. an individual species) and, just one group of organisms, large predatory reef fish. We used a group since few individual species were sufficiently abundant to allow appropriate analyses. Most species of large predatory fish are relatively rare in the species-rich assemblages of coral reefs. We chose this particular group as a model, because it is highly targeted by reef fisheries and responds well to protection from fishing in no-take reserves (Russ \& Alcala 1996a, 2004, Jennings \& Kaiser 1998). Clearly, rates of recovery in no-take reserves will be speciesspecific, site-specific, time-period specific and mechanism-specific. It is possible that the relatively clear results obtained in this study partially reflect the pooling 
of species into a group. The utility of spatial comparisons suggested by the present study may have been influenced by our choice of fish group and may not apply in other cases, even at the level of species that are highly targeted by fisheries. Differences in measured recovery rates of snapper Pagrus auratus in New Zealand reserves (e.g. Willis et al. 2003b, Denny et al. 2004) provide a clear example of where inferences about recovery rates may be problematic. A key point regarding the present study is that our group of pooled species consists of relatively long-lived organisms whose populations often have low rates of recruitment. We suggest that the longer-lived the target species is, or the more complex the variate of interest (e.g. species diversity, ecosystem structure), the more circumspect one should be in making conclusions about rates of recovery from once-only spatial comparisons of reserves and fished sites.

Furthermore, reserve effects are not restricted to the recovery of target species alone. The recovery of such predatory or 'keystone' species has considerable influence on the abundance of other species in the reserve (e.g. Castilla 1999, Babcock 2003, Shears \& Babcock 2003). Predicting the rates of development of such indirect effects of reserves, that often involve long-term changes in food webs and habitats, are likely best measured by temporal monitoring studies.

\section{CONCLUSIONS}

With similar levels of success of reserve protection, and using similar methods of census on the same target group in similar areas, one can make useful inferences about rates of recovery in no-take marine reserves. Such inferences are clearly not definitive, and should be viewed merely as guides to possible recovery rates. There is no substitute for properly designed monitoring studies that can not only determine recovery rates definitively, but also provide information on the mechanisms that drive the recovery rates.

Acknowledgements. This project was partially funded by the United Nations Environment Program (1983), the Great Barrier Reef Marine Park Authority (1985), a Pew Fellowship in Marine Conservation to G.R.R and A.C.A (1999 to 2002), and an Australian Research Council grant to G.R.R and A.C.A (2002 to 2004).

\section{LITERATURE CITED}

Babcock RC (2003) The New Zealand marine reserve experience: the science behind the politics. In: Hutchings $P$, Lunney D (eds) Conserving marine environments. Out of sight, out of mind? Royal Zoological Society of New South Wales, Mosman, p 108-119
Babcock RC, Kelly S, Shears NT, Walker JW, Willis TJ (1999) Changes in community structure in temperate marine reserves. Mar Ecol Prog Ser 189:125-134

Castilla JC (1999) Coastal marine communities: trends and perspectives from human exclusion experiments. Trends Ecol Evol 14:280-283

Côté IM, Mosquera I, Reynolds JD (2001) Effects of marine reserve characteristics on the protection of fish populations: a meta-analysis. J Fish Biol 59(Suppl A):178-189

Dayton PK, Sala E, Tegner MJ, Thrush SF (2000) Marine protected areas: parks, baselines, and fishery enhancement. Bull Mar Sci 66:617-634

Denny CM, Willis TJ, Babcock RC (2004) Rapid recolonisation of snapper Pagrus auratus: Sparidae within an offshore island marine reserve after implementation of no-take status. Mar Ecol Prog Ser 272:183-190

Edgar GJ, Barrett NS (1997) Short term monitoring of biotic change in Tasmanian marine reserves. J Exp Mar Biol Ecol 213:261-279

Edgar GJ, Barrett NS (1999) Effects of the declaration of marine reserves on Tasmanian reef fishes, invertebrates and plants. J Exp Mar Biol Ecol 242:107-144

Edgar GJ, Bustamante RH, Farina JM, Calvopina M, Martinez C, Toral-Granda MV (2005) Bias in evaluating the effects of marine protected areas: the importance of baseline data for the Galapagos Marine Reserve. Environ Conserv 31:212-218

English S, Wilkinson C, Baker V (1997) Survey manual for tropical marine resources, 2nd edn. Australian Institute of Marine Science, Townsville

Froese R, Pauly D (2003) Fishbase. Available at www.fishbase.org

Gell FR, Roberts CM (2002) The fishery effects of marine reserves and fishery closures. World Wildlife Fund-US, Washington, DC

Halpern BS (2003) The impact of marine reserves; do reserves work and does reserve size matter? Ecol Appl 13:S117-S137

Halpern BS, Warner RR (2002) Marine reserves have rapid and lasting effects. Ecol Lett 5:361-366

Hutchings JA (2000) Collapse and recovery of marine fishes. Nature 406:882-885

Jackson JBC, Kirby MX, Berger WH, Bjorndal KA and 15 others (2001) Historical overfishing and the recent collapse of coastal ecosystems. Science 293:629-638

Jennings S (2001) Patterns and prediction of population recovery in marine reserves. Rev Fish Biol Fish 10: 209-231

Jennings S, Kaiser MJ (1998) The effects of fishing on marine ecosystems. Adv Mar Biol 34:201-352

Jones GP, Cole RC, Battershill CN (1993) Marine reserves: do they work? In: Battershill CN, Schiel DR, Jones GP, Creese RG, MacDiarmid AB (eds) Proc 2nd Int Temperate Reef Symp. National Institute of Water and Atmospheric Research, Wellington, p 29-45

McClanahan TR (2000) Recovery of a coral reef keystone predator, Balistapus undulatus, in East African marine parks. Biol Conserv 94:191-198

McClanahan TR, Kaunda-Arara B (1996) Fishery recovery in a coral-reef marine park and its effect on the adjacent fishery. Conserv Biol 10:1187-1199

Mosquera I, Côté IM, Jennings S, Reynolds JD (2000) Conservation benefits of marine reserves for fish populations. Anim Conserv 3:321-332

Pauly D, Christensen V, Dalsgaard J, Froese R, Torres F (1998) Fishing down marine food webs. Science 279:860-863 
Pauly D, Christensen V, Guénette S, Pitcher T, Sumaila UR, Walters C, Watson R, Zeller D (2002) Towards sustainability in world fisheries. Nature 418:689-695

Polunin NVC (2002) Marine protected areas, fish and fisheries. In: Hart PJB, Reynolds JD (eds) Handbook of fish and fisheries, Vol 2. Blackwell Science, Oxford, p 293-318

Roberts CM (1995) Rapid build-up of fish biomass in a Caribbean marine reserve. Conserv Biol 9:815-826

Roberts CM, Polunin NVC (1991) Are marine reserves effective in management of reef fisheries? Rev Fish Biol Fish 1:65-91

Roberts CM, Bohnsack JA, Gell F, Hawkins JP, Goodridge R (2001) Effects of marine reserves on adjacent fisheries. Science 294:1920-1923

Rodwell LD, Barbier EB, Roberts CM, McClanahan TR (2003) The importance of habitat quality for marine reserve fishery linkages. Can J Fish Aquat Sci 60:171-181

Russ GR (2002) Yet another review of marine reserves as reef fisheries management tools. In: Sale PF (ed) Coral reef fishes: dynamics and diversity in a complex ecosystem. Academic Press, San Diego, CA, p 421-443

Russ GR, Alcala AC (1996a) Marine reserves: rates and patterns of recovery and decline in abundance of large predatory fish. Ecol Appl 6:947-961

Russ GR, Alcala AC (1996b) Do marine reserves export adult fish biomass? Evidence from Apo Island, central Philippines. Mar Ecol Prog Ser 132:1-9

Russ GR, Alcala AC (1999) Management histories of Sumilon and Apo marine reserves, Philippines, and their influence on national marine resource policy. Coral Reefs 18:307-319

Editorial responsibility: Otto Kinne (Editor-in-Chief), Oldendorf/Luhe, Germany
Russ GR, Alcala AC (2003) Marine reserves: rates and patterns of recovery and decline of predatory fish, 1983-2000. Ecol Appl 13:1553-1565

Russ GR, Alcala AC (2004) Marine reserves: long-term protection is required for full recovery of predatory fish populations. Oecologia 138:622-627

Russ GR, Alcala AC, Maypa AP (2003) Spillover from marine reserves: the case of Naso vlamingii at Apo Island, the Philippines. Mar Ecol Prog Ser 264:15-20

Russ GR, Alcala AC, Maypa AP, Calumpong HP, White AT (2004) Marine reserve benefits local fisheries. Ecol Appl 14:597-606

Shears NT, Babcock RC (2003) Continuing trophic cascade effects after 25 years of no-take marine reserve protection. Mar Ecol Prog Ser 246:1-16

Sobel JA, Dahlgren CP (2004) Marine reserves. A guide to science, design and use. Island Press, Washington, DC

Statistica (1995) Volume 1. General conventions and statistics I. Statsoft, Tulsa, OK

Underwood AJ (1981) Techniques of analysis of variance in experimental marine biology and ecology. Oceanogr Mar Biol Annu Rev 19:513-605

Willis TJ, Millar RB, Babcock RC, Tolimieri N (2003a) Burdens of evidence and the benefits of marine reserves: putting Descartes before des horse? Environ Conserv 30:97-103

Willis TJ, Millar RB, Babcock RC (2003b) Protection of exploited fishes in temperate regions: high density and biomass of snapper, Pagrus auratus (Sparidae) in northern New Zealand marine reserves. J Appl Ecol 40:214-227

Submitted: October 11, 2004; Accepted: March 8, 2005 Proofs received from author(s): April 26, 2005 